\title{
VECTORS OF VALUE ORIENTATION EVOLUTION OF PERSONAL ASSESSMENT AREA IN MODERN MEDIA DISCOURSE
}

\author{
Kseniya V. Kokina \\ Irkutsk State University, Irkutsk, Russia
}

\begin{abstract}
The urgent issue about the evolution of value orientations in modern linguistics is considered from the point of view of realization of contextual evaluative conceptualization in the texts of media discourse in line with the elaboration of the problem of determining the vectors of transformation processes.

The subject of the media discourse analysis is a personal value area of a human presented in the texts related to the basic value of family and children. In the article the concept of valorizing discourse is defined as a representative type of evaluative discoursivization. The means of structuring the evaluative relation to family as markers of value orientations and means of evaluative conceptualization are revealed on the basis of dynamic processual approach to discourse, methods of interpretative analysis and inference. Discursive analysis of the English and German texts of valorizing discourse helped to discover reframing of the conventional idea about the family, construction of the "real" value for a person instead of the established one, and also combination of value orientations in addition to another value concept. It is mentioned that revelation of the evolution vectors of value orientations is based on the Russian and German linguistic culture, and also the possibility of using this analysis concerning other linguistic cultures may take place.

It is established that the evolution processes in the modern personal axiosphere are defined by the processes of divergence or negation, inversion and integration.

Key words: value, evaluative conceptualization, evolution of the values, valorizing discourse, media text, Russian language, German language.

Citation. Kokina K.V. Vectors of Value Orientation Evolution of Personal Assessment Area in Modern Media Discourse. Vestnik Volgogradskogo gosudarstvennogo universiteta. Seriya 2. Yazykoznanie [Science Journal of Volgograd State University. Linguistics], 2019, vol. 18, no. 2, pp. 195-203. (in Russian). DOI: https://doi.org/10.15688/ jvolsu2.2019.2.17
\end{abstract}

УДК 81’42:070

Дата поступления статьи: 20.04.2018

ББК 81.055.1.5

Дата принятия статьи: 27.02.2019

\section{ВЕКТОРЫ ЭВОЛЮЦИИ ЦЕННОСТНЫХ ОРИЕНТИРОВ ПЕРСОНАЛЬНОЙ АКСИОСФЕРЫ В СОВРЕМЕННОМ МЕДИЙНОМ ДИСКУРСЕ}

\author{
Ксения Викторовна Кокина \\ Иркутский государственный университет, г. Иркутск, Россия
}

\begin{abstract}
Аннотация. Актуальный в современной лингвистике вопрос об эволюции ценностных ориентиров рассматривается с точки зрения реализации контекстуальной оценочной концептуализации в текстах медийного дискурса и в русле разработки проблемы определения векторов трансформационных процессов. В качестве предметной сферы анализа медийного дискурса избрано личностное ценностное пространство человека, представленное текстами, темой которых является отношение к базовой ценности «семья и дети». В статье уточняется понятие валоризирующего дискурса как репрезентативного вида оценочной дискурсивизации. На основе динамического процессуального подхода к дискурсу с применением методов интерпретативного анализа и инференции устанавливаются способы структурирования оценочного отношения к семье как маркеры ценностных ориентиров и способов оценочной концептуализации. Дис-
\end{abstract}




\section{МАТЕРИАЛЫ И СООБЩЕНИЯ}

курсивный анализ текстов валоризирующего дискурса на русском и немецком языках позволил определить возможности рефрейминга конвенционального представления о семье, конструирования «истинностной» ценности человека взамен устоявшейся, а также соединения ценностных смыслов в дополнение к другому ценностному понятию.

Делается вывод о том, что векторы эволюции ценностных ориентиров в современной персональной аксиосфере обусловлены их дивергенцией, отрицанием, инверсией и интеграцией. Отмечается возможность применения методики выявления эволюции ценностных ориентиров при изучении других лингвокультур, в которых характеризуются эволюционные процессы.

Ключевые слова: ценность, оценочная концептуализация, эволюция ценностей, валоризирующий дискурс, медиатекст, русский язык, немецкий язык.

Цитирование. Кокина К. В. Векторы эволюции ценностных ориентиров персональной аксиосферы в современном медийном дискурсе // Вестник Волгоградского государственного университета. Серия 2, Языкознание. - 2019. - Т. 18, № 2. - C. 195-203. - DOI: https://doi.org/10.15688/jvolsu2.2019.2.17

\section{Введение. Валоризирующий дискурс и его роль в формировании ценностей}

Развитие информационного общества сопровождается коренными изменениями форм бытия и коммуникации, способов порождения и мультиплицирования мнения и оценки, интенсивной трансформацией ценностей в современной культуре. В процессе цивилизационных сдвигов, по мнению ученых, происходит «слом», «дрейф» традиционных ценностей [Кузнецов, 2017], эволюция ценностных ориентиров [Лингвистика и аксиология..., 2011]. Наиболее репрезентативен в этом плане медиадискурс, поскольку медийное информационное коммуникативное пространство становится пространством репрезентации современных способов формулирования, формирования и продвижения наиболее значимых ценностных смыслов. Они ориентированы прежде всего на субъектно и оценочно центрированную когнитивную систему адресата. Такая тенденция характеризуется переосмыслением и столкновением ценностей коллективных и индивидуальных, универсальных и культурно специфичных, традиционных и новых. Ценности являются определенным образом сгруппированными принципами, предпочтениями, нормами, идеалами, формирующими «аксиосферу» и аксиологическое измерение языка, онтологически отражающего экзистенциальный статус переживания человеком такого состояния, которое В.В. Ильин назвал «между миром реального и миром должного, сущностного, желаемого» [Ильин, 2005]. Кроме того, ценности рассматриваются как вечные объекты [Whitehead, 1967], воплощающи- еся в актуальные сущности и становящиеся внутренней реальностью явления для человека и общества. Включенность человека в «вечный мир» ценностей определяется благодаря инкультурации и социализации по оси семиотического континуума передачи особо значимых смыслов, формирующих в обществе разделенное знание. Вместе с тем в аспекте дискурсивной самоидентификации говорящего они могут иметь относительное, индивидуально-личностное воплощение в дискурсе «здесь и сейчас», в котором реализуется конструирование ценностных смыслов, высказывается субъектное интерпретативное отношение человека к миру, социуму, ближайшему окружению, собственным целевым ориентирам и установкам, сформировавшимся на базе опыта и моделей освоенного знания, которые составляют основу, с одной стороны, для личностной самоидентификации человека, с другой - для возникновения общих смыслов в социальной коммуникации.

Формирование оценочного отношения к воспринимаемому и осмысляемому объекту реализуется посредством определенных дискурсивных стратегий и конструирует контекстуальный ценностный смысл по отношению к предмету осмысления - дискурсному топику. Концептуальное пространство оценки - маркера глубинного уровня концептуализации -представлено непрерывной референцией в соответствии со шкалой инференции к освоенной системе ценностей с двумя экстремумами «хорошо» - «плохо» на основе эталонов, корректирующих инференцию. Структуры размышления и понимания, в частности в виде фреймов, с необходимостью возводятся к ценностным 
ориентирам [Lakoff, 1987, p. 235]. В работах Н.Н. Болдырева показано, что соотнесение, оценивание воспринимаемых объектов с уже существующими концептами и категориями отражает интерпретацию как освоение мира человеком, составляя оценочную концептуализацию [Болдырев, 2002; 2004]. Она происходит, как это показано С.Н. Плотниковой и Е.Ф. Серебренниковой [Плотникова, Серебренникова, 2013], в траектории дискурсивизации, что репрезентируется в ценностных ориентирах дискурса как «живого» субъектного знания, мнения, оценки. Валоризация - повышение или понижение ценностного статуса дискурсного топика - осевой процесс оценочной концептуализации. Дискурс, в котором реализуется базовая интенция говорящего к валоризации, проецирующей целостную траекторию дискурсивизации, Е.Ф. Серебренникова предлагает определять как валоризирующий тип дискурса [Серебренникова, 2015; 2017]. Виды валоризирующего дискурса представлены текстами, в которых выражено собственно оценочное суждение, и текстами, в которых смыслообразование выстроено как структурирование оценочного отношения к объекту [Лингвистика и аксиология..., 2011].

В исследованиях Е.Ф. Серебренниковой показано, что значимости, восходящие к нравственным, мировоззренческим или эстетическим нормам, идеалам и преференциям, в процессе валоризации осмысляемого приобретают характер ценностей, ценностных ориентиров и установок, а также что в континууме эволюции культуры и общества формируется аксиологический континуум, изменяющийся под влиянием факторов «хронотопа», «духа времени» и телеологии человека, на которую безусловное влияние оказывает понимание конечности жизни (см., например: [Серебренникова, 2013]).

Валоризирующий дискурс, таким образом, является наиболее репрезентативным для анализа оценочной дискурсивизации; процесс его реализации, смыслопорождение от интенциональности (термин Дж. Серля: [Searle, 1983, p. 79]) до дестинации, представляет собой конструирование оценочного отношения в дискурсе в данных параметрах коммуникации.

В связи с этим актуальным является дальнейшее исследование проблемы эволю- ции ценностных ориентиров, разрабатываемой в аксиологии [Ильин, 2005; Каган, 1997] и лингвоаксиологии [Арутюнова, 1988; 1999; Вольф, 2002; Карасик, 2002], на основе анализа медийного валоризирующего дискурса предметной сферы личностного ценностного пространства.

На современном этапе развития культуры и общества наблюдаются изменения, обусловленные более активной ролью субъекта в социальной жизни и открытостью личной сферы тенденциям и изменениям в обществе и культуре (подробно об этом см.: [Ахиезер, Сайко, 2006]). Следовательно, важным представляется изучение трансформации ценностного отношения в дискурсе с целью выявления современных тенденций изменений личностной аксиосферы.

\section{Методология и материал исследования}

Методология нашего исследования опирается на положения теории ценностей, оценки, динамический, интерпретативный, процессуальный подходы к изучению дискурса с точки зрения его когнитивной природы в модели траектории дискурсивизации [Плотникова, Серебренникова, 2013], а также на параметры и категории аксиологически ориентированной лингвистики [Арутюнова, 1988; 1999; Вольф, 2002; Казыдуб, 2009; Карасик, 2002; Серебренникова, 2017; Слышкин, 2004]. В центре нашего внимания находятся процессы концептуализации и категоризации с точки зрения их актуальной репрезентации в дискурсе как субъектно обусловленных интерпретативных процессов конструирования особо значимого смысла. Установление способов репрезентации оценочной концептуализации в валоризирующем медийном дискурсе представляет собой одну из актуальных проблем аксиологически ориентированной лингвистики.

Один из значимых «топосов» означивания личностной персональной сферы и одна из базовых ценностей наряду с такими, как добро, любовь, жизнь, - это ценность «семья и дети». Создание и существование семьи, рождение детей, являющихся в мире реального основным способом продолжения бытия народа, в ценностном плане видится как некое защитное поле вокруг человека, которое представляет ценностные ориентиры обеспе- 


\section{МАТЕРИАЛЫ И СООБЩЕНИЯ}

чения будущего и естественного пути самореализации.

Способы структурирования оценочного отношения к семье как маркеры ценностных ориентиров определяются нами на материале медиатекстов на русском и немецком языках, включенных в валоризирующий дискурс. Такие тексты рассматриваются как единый массив, без учета специфики русской и немецкой лингвокультур. Предметную сферу анализа составляет личностное ценностное пространство человека, представленное текстами, темой которых является отношение к базовой ценности «семья и дети». Источником материала для анализа послужили интернет-ресурсы; корпус медиатекстов отобран в результате поиска по ключевым словам персональной сферы мнения и оценки, например: по-моему, семья - это...; для меня дети - это...; думаю, что семья...; семья сегодня...; семьяэто главное; семья - это не главное; Familie ist das wichtgste im Leben; Glücklich mit Kindern, frei vom Kind.

В рамках статьи представим анализ шести текстов (см. список источников), отобранных методом случайной выборки из общего корпуса текстов валоризирующего дискурса, дискурсным топиком которых является отношение к семье и детям. Этот материал репрезентативен с точки зрения отражения способов структурирования оценочного отношения к семье как базовой ценности, поскольку значимость, восходящая к нравственной норме «семья и дети», в валоризирующем типе дискурса приобретает в континууме эволюции культуры характер ценности или ее антипода - антиценности.

\section{Способы репрезентации ценностных изменений}

Выявлены 3 способа репрезентации изменений в отношении ценностных ориентиров в валоризирующем дискурсе.

Cпособ 1. Структурирование референциальной ценностной оппозиции «раньше - сейчас»: устойчивое понимание семьи как традиционной базовой ценности / актуальная оценочная концептуализация понятия семьи. Такой способ реализуется в статьях «Дети - это счастье, а разве может быть счастья слиш- ком много?» (ПОЛАВКАМ), «Чайлдфри: как возникает и стоит ли бороться» (ОБ).

Устойчивое понимание семьи как традиционной ценности раскрывается в статье посредством позитивных ассерций - оценочных суждений о семье как цели и смысле жизни.

Семья - это: будущее рода и всего человечества (ПОЛАВКАМ); главная иель в жизни множества людей (ПОЛАВКАМ).

Абсолютная ценность семьи связана с рождением детей, что подтверждается переносом понимания семьи в координаты базовой нравственной антиценности персональной сферы человека - позора: бездетность считалась позором (ПОЛАВКАМ).

При этом глагол коллективного мнения и оценки считаться в прошедшем времени задает ретроспективную проекцию, имплицирующую изменение данного ориентира в настоящее время.

Как видим, оценочная концептуализация осуществляется благодаря апелляции к аксиологемам, являющимся именами ценностно насыщенных концептов «Будущее», «Главная цель в жизни», а также с опорой на воспроизведение доксастического мнения с точки зрения его изменения.

Актуальная, изменившаяся оценочная концептуализация реализуется в описании этого понятия как «лучшей жизни», в результате чего смысложизненная ценность «семья» теряет свою значимость.

В отличие от ассерций ценностного понимания семьи «раньше», новая ценностная ориентация - «лучшей жизни» - конструируется путем проекции в будущее; аксиологической стратегией является валоризация будущего, которое требует изменения отношения человека к себе «здесь и сейчас»: жизнь у человека одна, женщина имеет право делать выбор жизненного пути по своему усмотрению. Грамматическую основу такой дискурсивизации составляет будущее время глагола-предиката, выстраивающего желаемый ориентир «лучшей жизни» в координатах ситуации жизни «без детей». К аргументам в реализации стратегии относятся:

- подведение под ценностный ориентир «насыщенность жизни»: жизнь будет насыщенна без мальшей (ОБ); 
- подведение под ценностный ориентир «успех», «карьера», «самореализация» в векторе экстремума «плохо»: дети станут помехой карьере и самореализаиии (ОБ);

- подведение под непреодолимую альтернативу (жизнь или ребенок) и совершение выбора автором вместо людей, обобщающее утверждение о том, что и как чувствуют люди: люди сегодня не хотят жертвовать своей жизнью ради ребенка (ОБ); субъект дискурса принимает позицию коллективного субъекта оценочного суждения;

- подведение под новый концепт «Чайлдфри»; концептуальное заимствование в российскую инфосферу из глобальной инфосферы в форме траснскрипции англоязычного слова-имени концепта маркирует его принадлежность сфере моды, актуальных «трендов» современной культуры.

В анализируемых текстах аргумент обосновывается путем апелляции к «эталонной», прецедентной сакральной ситуации жертвования, причем в качестве жертвы представляется сам человек, его жизнь. Следует отметить, что заголовок текста, сформулированный в виде постановки проблемы, вопроса Чайлдфри: как возникает и стоит ли бороться (ОБ), также является средством валоризации данной персональной сферы человека и индикатором происходящей эволюции ценностей. Дискурсивный анализ примеров валоризирующего дискурса демонстрирует изменение, возможность рефрейминга стереотипного, конвенционального представления о семье.

Cпособ 2. Выражение сомнения в базовой ценности или ее однозначное отрицание на основе создаваемых в дискурсе новых ценностных ориентиров. Сомнение и отрицание конструируются в смысловом пространстве «sollen / sein» как основной морально-нравственной альтернативы человека, сформулированной еще И. Кантом.

Данный способ наиболее полно представлен в статьях «Familie: besser leben ohne Kinder» (Eltern) - «Семья: лучше жить без детей» (здесь и далее перевод с немецкого наш. $-K . K$.) и «Frau soll frei vom Kind sein» (WZ) -«Женщина должна быть свободна от ребенка», в которых конструируется новое ценностное осмысление семьи, «семьи без детей» посредством:
- постановки под сомнение устойчивой ценности «семья и дети» как базовой для женщины путем введения новообразования Famimami с ироничным карикатурным эффектом (неологизм Famimami создан на основе сложения двух слов Familie (семья) и Mutter (мама) и означает в контексте «мутировавших» в семейное существо женщин). Оценочная концептуализация здесь отражает негативное отношение к базовой ценности, что приводит к изменению ценностного смысла посредством перестановки ценности семьи в координаты антиценности;

- категоризации отрицательного отношения к материнству в виде негативных, достаточно категорических утверждений, введения аксиологемы «материнство» в отрицательный контекст: zweifache Mutter geniesst ihre Elternschaft nicht besonders (WZ) - «дважды мать не особо наслаждается материнством»; die Mutterschaft besteht aus üblen Schmerzen bei der Geburt, dem Verzicht auf sämtliche Lebensfreude (Eltern) - «материнство состоит из неприятных болей при рождении ребенка и отказа от всех радостей жизни»; der Dauerbelastung durch Job, Haushalt und das Erziehen kleiner Egoisten sowie dem geradezu zwangsläufigen Verdummen und Verfetten (Eltern) - «постоянная нагрузка на работе, домашнее хозяйство и воспитание маленьких эгоистов, а также почти неизбежное отупление и ожирение». В результате такой контекстуализации происходит конструирование новой симулятивной ориентации ценностного смысла: семья не может рассматриваться в качестве блага и ценностно положительного понятия;

- апелляции к личному опыту женщин. Для этого используется такой аргумент, как экземплификация, личное свидетельство: отрицание «семьи с детьми» осуществляется на основе воспроизведения отрицательного опыта реальной, конкретной матери двух детей; высказывание персонализируется, рассказ ведется от первого лица в форме диалога, доверительного разговора о реальности повседневной жизни, исповедального мнения о сущности происходящего: Ich persönlich habe in meinem ganzen Leben nichts erlebt, das (Kindergeburt) mir so weh getan hätte. Erstens tut es verdammt weh. Und zweitens, haben Sie 
sich schon einmal die Brüste einer stillenden Frau angesehen? Appetitlich ist das nicht. Von Schrunden und Rissen entstellte Brüste, an denen die Milch herunterläuft, igittigitt! Kinder zu bekommen heißt, sich bedingungslos und unwiderruflich zu verpflichten (Eltern) - «Лично я в своей жизни никогда не испытывала такой боли, как при рождении ребенка. Вопервых, это безумно больно, во-вторых, вы когда-нибудь видели грудь кормящей женщины? Это далеко не привлекательно. Обезображенная от растяжек и трещин грудь, по которой стекает молоко, фуфуфу. Завести детей - это безоговорочно и окончательно взять на себя обязательство так жить». Воспроизведение личного опыта имплицирует ожидание эмпатии от адресата. Новый ориентир, противоположный устойчивой ценности, репрезентируется как существующая реальность, разделяемая и переживаемая многими, что представляет собой контекстную актуальную оценочную концептуализацию ценности семьи в качестве псевдоценности и ее репрезентацию на данных основаниях.

Используется номинативный, а не предикативный способ означивания жизни в связи с рождением детей: und das (Kinder, Nerven usw) für den Rest des Lebens (Eltern) «и это (дети, нервы и т. д.) до конца жизни»; ...dass Sie Ihr «Leben davor» zu Grabe tragen müssen (Eltern) - «что Вы должны похоронить свою жизнь “до”»; Ihr Leben spielt sich nur noch in den Zeitfenstern ab, die Ihr Kind Ihnen lässt (Eltern) - «Ваша жизнь происходит только в те промежутки времени, которые Вам дает Ваш ребенок»; Verzicht auf sämtliche Lebensfreude (Eltern) - «отказ от всех радостей жизни». Репрезентация представлений о деторождении как элементе фрейма «Жизнь» способствует восприятию жизни как статичной, застойной, не имеющей для матери никакого развития, превращает видение жизни в ее антипод - безжизненность и, таким образом, способствует актуальной оценочной концептуализации семьи как не совсем или вовсе неприемлемого образа существования человека.

Создаваемое данным способом отрицание устойчивой ценности «семья и дети», как и в случае первого способа, приводит к конструированию «истинностной» ценности чело- века, которая, по сути, проявляется как «сверхценность» личностного бытия - ценность жизни отдельного человека как жизни для себя (sein) в противоположность жизни для других - ради семьи, ради детей (sollen). Эти направления дискурсивизации выражены в ценностном суждении-кредо: Besser leben ohne Kinder (WZ) - «Лучше жить без детей».

Cпособ 3. Компромиссная аргументация на основе интегральной ценности.

Анализ текстов интервью с психологом Анатолием Некрасовым «Главное предназначение человека - быть счастливым» (КазВед) и с телеведущей Туттой Ларсен «“Тутта Ларсен”. Интервью. Телеведущая» (Слимим) позволяет говорить о таком феномене в валоризирующем дискурсе, как оценочная концептуализация посредством создания на фоне двух ценностей одной, интегральной ценности, более значимой с точки зрения видения целей, смысла жизни, ее предназначения.

В указанных интервью ценности «семья и дети» и «карьера» не противопоставляются, а дополняют друг друга: Постоянный труд $u$ наличие брака - это еще не предназначение (КазВед); Без семьи тоже можно жить, но... (КазВед); Часто бывает так, что человек реализовался в профессии, но упустил из внимания семью, отношения с детьми, здоровье, полноту жизни, счастье... Если в пирамиде не хватает хотя бы одного из этих важных блоков, человека нельзя назвать понастоящему счастливым (КазВед).

Данные тезисы эксплицируют новую ценность - «быть счастливым», на фоне которой понятия семьи, детей, карьеры уходят на второй план. Приведем еще несколько высказываний, выражающих именно эту ценность: Ведь это и есть главное и основное предназначение человека на Земле - быть полноценно счастливым (КазВед); Нужно очень любить свое дело, быть этим искренне увлеченным и постоянно совершенствоваться, узнавать что-то новое в своей профессии, учиться, не останавливаться (Слимим); Если женщина будет чувствовать себя счастливой, то счастлива будет и ее семья (Слимим); Уметь находить гармонию внутри себя, быть благодарными за то, что есть, но при этом не бояться открывать и познавать новое (Слимим). 
Актуальная оценочная концептуализация происходит в русле концепта «Предназначение» в результате конструирования интегральной ценности - формулы счастья: «гармония, гармонизация, самореализация». Аргументация направлена на соединение ценностных смыслов «семья и дети» и «работа, карьера» в дополнение к ценностному понятию счастья и самореализации как в семье, так в жизни в целом.

\section{Заключение}

Таким образом, векторы эволюции ценностных ориентиров в современной персональной аксиосфере определяются их дивергенцией, отрицанием, инверсией и интеграцией. Дивергенция обнаруживается в расхождении ценностных смыслов, возникновении двух вариантов понимания ценности по двум экстремумам шкалы оценивания «хорошо» - «плохо». Отрицание проявляется в абсолютном отвержении устойчивой ценности как базовой для человека на основе высказываний адресата и замещение ее вновь созданной псевдоценностью. Инверсия проявляется при изменении статуса ценности. Как интеграцию можно определить трансформационный процесс внедрения «третьей» ценности, на фоне которой дивергенция первых двух теряет свое значение. Анализируемые способы дискурсивной реализации оценочных процессов установлены на основе русской и немецкой лингвокультур, однако также могут быть применены в отношении других лингвокультур, характеризующих эволюционные процессы современной персональной аксиосферы индивида той или иной культуры. Изучение оценочной концептуализации в валоризирующем дискурсе как эволюции ценностных ориентиров показывает актуальность данного направления исследования и необходимость более глубокого изучения, в частности, дискурсивных способов валоризации ценностных ориентиров на уровне установок, интенциональностей, стратегий и предназначенности данного типа дискурса.

\section{СПИСОК ЛИТЕРАТУРЫ}

Арутюнова Н. Д., 1988. Типы языковых значений: Оценка. Событие. Факт. М. : Наука. 341 с.
Арутюнова Н. Д., 1999. Язык и мир человека. 2-е изд. М. : Языки русской культуры. 896 с.

Ахиезер А. С., Сайко Э. В., 2006. Субъект во времени социального бытия: историческое выполнение пространственно-временного континуума социальной эволюции / отв. ред. Э. В. Сайко; Ин-т всеобщ. истории РАН. М. : Наука. 600 c.

Болдырев Н. Н., 2002. Структура и принципы формирования оценочных категорий // С любовью к языку : сб. науч. тр. / отв. ред. В. А. Виноградов. М. ; Воронеж : ИЯ РАН, Воронеж. гос. ун-т. С. 103-114.

Болдырев Н. Н., 2004. Свойства и границы оценочных категорий в свете новых представлений о процессах категоризации // Языковые категории: Границы и свойства : Материалы докл. Междунар. науч. конф. (г. Минск, 2223 марта 2004 г.). Минск : Мин. гос. лингв. ун-т. С. $14-16$.

Вольф Е. М., 2002. Функциональная семантика оценки. М. : Едиториал УРСС. 280 с.

Ильин В. В., 2005. Аксиология. М. : Изд-во МГУ. 216 с.

Каган М. С., 1997. Философская теория ценности. СПб. : Петрополис. 205 c.

Казыдуб Н. Н., 2009. Аксиологические системы в языке и речи // Вестник Иркутского государственного лингвистического университета: Языкознание. № 2 (6). С. 132-137.

Карасик В. И., 2002. Языковой круг: личность, концепты, дискурс. Волгоград : Перемена. 477 с.

Кузнецов И. М., 2017. Ценностные ориентиры и социально-политические установки россиян // Coциологические исследования. № 1. С. 47-55.

Лингвистика и аксиология..., 2011. Лингвистика и аксиология: этносемиометрия ценностных смыслов : колл. моногр. / Е. Ф. Серебренникова, Н. П. Антипьев, Л. Г. Викулова и др. М. : ТЕЗАУРУС. $352 \mathrm{c}$.

Плотникова С. Н., Серебренникова Е. Ф., 2013. Когнитивная траектория дискурсивизации: дестинация, стратегия, технология // Вестник Иркутского государственного лингвистического университета. № 1 (22). С. 183-188.

Серебренникова Е. Ф., 2013. Аксиологическая параметризация социального дискурса // Вестник Иркутского государственного лингвистического университета: Языкознание. № 2 (23). C. $13-18$.

Серебренникова Е. Ф., 2015. Аксиологические аспекты реализации дискурсивной позиции как точки зрения // Вестник Московского государственного лингвистического университета. Вып. 3 (714). С. 84-93.

Серебренникова Е. Ф., 2017. Текст и дискурс: на пути к формированию методологии и инст- 
рументария лингвоаксиологического анализа // Текст: дискурсивное проявление и коммуникативная практика : сб. науч. ст. в честь юбилея д-ра филол. наук, проф. Л. Г. Викуловой / под общ. ред. Е. Г. Таревой. М. : МГПУ. Языки Народов Мира. С. 34-45.

Слышкин Г. Г., 2004. Лингвокультурный концепт как системное образование // Вестник Воронежского государственного университета. Серия: Лингвистика и межкультурная коммуникация. № 1. С. 29-34.

Lakoff G., 1987. Women, fire, and dangerous things. Chicago : University of Chicago Press. 632 p.

Searle J., 1983. Intentionality: An Essay in the Philosophy of Mind. Cambridge : Cambridge University Press. 278 p.

Whitehead A. N., 1967. Process and reality: an essay in cosmology. New York : Macmillan company. 546 p.

\section{ИСТОЧНИКИ}

КазВед - Анатолий Некрасов: Главное предназначение человека - быть счастливым // Казанские ведомости. URL: https://kazved.ru/article/ 63198.aspx (дата обращения: 09.03.2018).

$O Б$ - Чайлдфри: как возникает и стоит ли бороться // Обозреватель.ua. URL: https:// www.obozrevatel.com/lady/psychology/ chajldfri-kak-voznikaet-i-stoit-li-borotsya.htm (дата обращения: 24.11.2017).

ПОЛАВКАМ - «Дети - это счастье, а разве может быть счастья слишком много?» // ПОЛАВКАМ. Семья в тренде. URL: https:// polavkam.livejournal.com/65394.html (дата обращения: 26.02.2018).

Слимим - «Тутта Ларсен». Интервью. Телеведущая // Слимим. URL: https://slimim.diet/41906/tuttalarsen/ (дата обращения: 09.03.2018).

Eltern - Eltern. URL: https://www.eltern.de/familieund-urlaub/familienleben/leseprobe-no-kid.html

$W Z$ - Frau soll frei vom Kind sein // Westdeutsche Zeitung. URL: https:/www.wz.de/kultur/buch/ frau-soll-frei-vom-kind-sein_aid-31485537 (дата обращения: 09.03.2018).

\section{REFERENCES}

Arutyunova N.D., 1988. Tipy yazykovykh znacheniy: Otsenka. Sobytie. Fakt [Types of Language Meanings. Evaluation. Event. Fact]. Moscow, Nauka Publ. 341 p.

Arutyunova N.D., 1999. Yazyk i mir cheloveka [Language and the Human World]. Moscow, Yazyki russkoy kultury Publ. 896 p.
Akhiezer A.S., Sayko E.V., 2006. Subyekt vo vremeni sotsialnogo bytiya: istoricheskoe vypolnenie prostranstvenno-vremennogo kontinuuma sotsialnoy evolyutsii [A Subject at the Time of Social Existence: Historical Performance of the Space-Time Continuum of Social Evolution]. Moscow, Nauka Publ. 600 p.

Boldyrev N.N., 2002. Struktura i printsipy formirovaniya otsenochnykh kategoriy [Structure and Principles of Forming Evaluation Categories]. Vinogradov V.A., ed. S lyubovyu $k$ yazyku: sb. nauch. tr. [With Love to Language. Collection of Scientific Works]. Voronezh, IYa RAN, Voronezhskiy gosudarstvennyy universitet, pp. 103-114.

Boldyrev N.N., 2004. Svoystva i granitsy otsenochnykh kategoriy $\mathrm{v}$ svete novykh predstavleniy o protsessakh kategorizatsii [Properties and Boundaries of Evaluation Categories in the Light of New Concepts of Categorization Processes]. Yazykovye kategorii: Granitsy i svoystva: Materialy dokl. Mezhdunar. nauch. konf. (g. Minsk, 22-23 marta 2004 g.) [Proceedings of the International Scientific Conference "Language Categories: Boundaries and Properties"]. Minsk, Minskiy gosudarstvennyy lingvisticheskiy universitet, pp. 14-16.

Volf E.M., 2002. Funktsionalnaya semantika otsenki [Functional Evaluation Semantics]. Moscow, Editorial URSS Publ. 280 p.

Ilyin V.V., 2005. Aksiologiya [Axiology]. Moscow, Izd-vo MGU. $216 \mathrm{p}$

Kagan M.S., 1997. Filosofskaya teoriya tsennosti [The Philosophical Theory of Value]. Saint Petersburg, Petropolis Publ. 205p.

Kazydub N.N., 2009. Aksiologicheskie sistemy v yazyke i rechi [Value Systems in Language and Speech]. Vestnik Irkutskogo gosudarstvennogo lingvisticheskogo universiteta [ISLU Philological Review], no. 2 (6), pp. 132-137.

Karasik V.I., 2002. Yazykovoy krug: lichnost, kontsepty, diskurs [Language Circle: Personality, Concepts, Discourse]. Volgograd, Peremena Publ. 477 p.

Kuznetsov I.M., 2017. Tsennostnye orientiry i sotsialnopoliticheskie ustanovki rossiyan [Values and Socio-Political Attitudes in Contemporary Russia]. Sotsiologicheskie issledovaniya [Sociological Studies], no. 1, pp. 47-55.

Serebrennikova E.F., Vikulova L.G., Antipyev N.P., Ladygin Yu.A., Malinovich Yu.M., Plotnikova S.N., Tareva E.G., Khakhalova S.A., Kazydub N.N., Litvinenko T.E., Semenova T.I., Gotlib O.M., Malinovich M.V., Sharunov A.I., Kulagina O.A., 2011. Lingvistika i aksiologiya: etnosemiometriya tsennostnykh smyslov: koll. monografiya [Linguistics and Axiology: Ethno-Semiometry of 
Value Meanings: Collective Monograph]. Moscow, TEZAURUS Publ. $352 \mathrm{p}$.

Plotnikova S.N., Serebrennikova E.F., 2013. Kognitivnaya traektoriya diskursivizatsii: destinatsiya, strategiya, tekhnologiya [The Cognitive Trajectory of Discursivization: Destination, Strategy, Technology]. Vestnik Irkutskogo gosudarstvennogo lingvisticheskogo universiteta [ISLU Philological Review], no. 1 (22), pp. 183-188.

Serebrennikova E.F., 2013. Aksiologicheskaya parametrizatsiya sotsialnogo diskursa [Axiological Parametrization of Social Discourse]. Vestnik Irkutskogo gosudarstvennogo lingvisticheskogo universiteta [ISLU Philological Review], no. 2(23), pp. 13-18.

Serebrennikova E.F., 2015. Aksiologicheskie aspekty realizatsii diskursivnoy pozitsii kak tochki zreniya [Axiological Aspects of Realization of Discursive Position as Viewpoint]. Vestnik Irkutskogo gosudarstvennogo lingvisticheskogo universiteta [Vestnik of Moscow State Linguistic University], iss. 3 (714), pp. 84-93.

Serebrennikova E.F., 2017. Tekst i diskurs: na puti k formirovaniyu metodologii i instrumentariya lingvoaksiologicheskogo analiza [Text and Discourse: On the Way to Forming the Methodology and Tools of Linguoaxiological Analysis]. Tareva E.G., ed. Tekst: diskursivnoe proyavlenie i kommunikativnaya praktika: sb. nauch. st. v chest yubileyad-ra filol. nauk, prof. L.G. Vikulovoy [Text: Manifestation of the Discursive and Communicative Practice: Collection of Scientific Works in Honor of the Anniversary of Doctor of Sciences (Philology), Professor L.G. Vikulova]. Moscow, MGPU, Yazyki Narodov Mira Publ., pp. 34-45.

Slyshkin G.G., 2004. Lingvokulturnyy kontsept kak sistemnoe obrazovanie [Linguocultural Concept as a Systemic Formation]. Vestnik Voronezhskogo gosudarstvennogo universiteta. Seriya:
Lingvistika i mezhkulturnaya kommunikatsiya [Proceedings of Voronezh State University. Series: Linguistics and Intercultural Communication], no. 1, pp. 29-34.

Lakoff G., 1987. Woman, Fire, and Dangerous Things. Chicago, University of Chicago Press. 632 p.

Searle J., 1983. Intentionality: An Essay in the Philosophy of Mind. Cambridge, Cambridge University Press. 278 p.

Whitehead A.N., 1967. Process and Reality: An Essay in Cosmology. New York, Macmillan Company Publ. 546 p.

\section{SOURCES}

Nekrasov A. Glavnoe prednaznachenie cheloveka byt schastlivym [The Main Purpose of Man is to Be Happy]. Kazanskie vedomosti. URL: https://kazved.ru/article/63198.aspx (accessed 9 March 2018).

Chayldfri: kak voznikaet i stoit li borotsya [Childfree: How Does it Occur and Is It Worth to Fight]. Obozrevatel.ua. URL: https://www.obozrevatel.com /lady/psychology/chajldfri-kak-voznikaet-i-stoit-liborotsya.htm (accessed 24 November 2017).

Deti - eto schastye, a razve mozhet byt schastya slishkom mnogo? [Children are Happiness, but Can Happiness Be too Much?]. POLAVKAM. Semya v trende. URL: https://polavkam.livejournal.com/ 65394.html (accessed 26 February 2018).

«Tutta Larsen». Intervyu. Televedushchaya ["Tutta Larsen". Interview. TV Presenter]. Slimim. URL: https://slimim.diet/41906/tutta-larsen/ (accessed 9 March 2018).

Eltern. URL: https://www.eltern.de/familie-und-urlaub/ familienleben/leseprobe-no-kid.html

Frau soll frei vom Kind sein. Westdeutsche Zeitung. URL: https://www.wz.de/kultur/buch/frau-sollfrei-vom-kind-sein_aid-31485537 (accessed 9 March 2018).

\section{Information about the Author}

Kseniya V. Kokina, Postgraduate Student, Department of Romano-Germanic Philology; Lecturer, Department of Oriental and Area Studies in the APR, Irkutsk State University, Lenina St., 8, 664025 Irkutsk, Russia, kseniya_kokina@hotmail.com, https://orcid.org/0000-0002-0576-1138

\section{Информация об авторе}

Ксения Викторовна Кокина, аспирант кафедры романо-германской филологии; преподаватель кафедры востоковедения и регионоведения Азиатско-Тихоокеанского региона, Иркутский государственный университет, ул. Ленина 8, 664025 г. Иркутск, Россия, kseniya_kokina@hotmail.com, https://orcid.org/0000-0002-0576-1138 